\title{
Prediction model for the analysis of the haptic perception of textiles
}

\begin{abstract}
In order to stand out from the competition, the quality of a product as subjectively perceived by the customer is becoming increasingly important. If one wants to meet the comprehensive customer requirements, it is no longer sufficient today to develop a product that focuses only on the functional aspects, but it must also fulfil the sensory requirements at the same time. In this paper, a systematic approach is described that first describes the objectification of customer language for describing the textile haptics of automotive interior materials ( 11 headliners and 15 seat materials). For this purpose, ten textile-specific descriptors were developed in an expert panel. The descriptors used and the measurement of the human-haptic system are summarized in 4 main groups: 1. warmth/cold sensation, 2. friction properties, 3. deformation, 4. surface/topography. Furthermore, the humantactile parameters (pressure, speed) that humans exert when touching textile surfaces were determined. The human-sensory product evaluation of the textiles was carried out with 116 test persons. Comparative statistical analyses of the technical parameters (e.g. roughness, friction coefficient, wetting index, deformation) and the human characteristics made it possible to create a prognosis model for determining the quality perception of textile car interior materials.
\end{abstract}

Keywords: Haptic, Perception, Prediction model, Tactile parameters, Human sensory, Descriptors
Volume 7 Issue 3 - 202 I

\author{
Falk Simon,' Martin Strangfeld,' Lars \\ Gussen, ${ }^{2}$ Serge Lang, ${ }^{3}$ Bianca-Michaela \\ Wölfling, ${ }^{3}$ Harald Notz-Lajtkep ${ }^{3}$ \\ 'FILK Freiberg Institute gGmbH, Department Surfaces, Germany \\ ${ }^{2}$ Laboratory for Machine Tools and Production Engineering WZL \\ of RWTH Aachen Chair of Production Metrology and Quality \\ Management, Department Quality Intelligence, Germany \\ ${ }^{3}$ Hohenstein Institut für Textilinnovation gGmbH, Department \\ Life Science \& Care, Germany
}
Correspondence: Falk Simon, FILK Freiberg Institute gGmbH, Meißner Ring I-5, 09599 Freiberg, Sachsen, Germany, Tel +49 (0)373। 366 I77, Fax +49 (0)373। 366 I30, Email falk.simon@filkfreiberg.de Lars Gussen, Laboratory for Machine Tools and Production Engineering WZL of RWTH Aachen, Campus-Boulevard 30, 52074 Aachen, Nordrhein-Westfalen, Germany, Tel +49(0)24I 8027 I25, Fax +49(0)24I $80627 \mid 25$, Email l.gussen@wzl.rwth-aachen.de Dr. Bianca-Michaela Wölfling, Hohenstein Institut für Textilinnovation gGmbH, Schlosssteige I, 74357 Boennigheim, Baden-Württemberg, Germany, Tel +49(0)7।43 27I 370, Fax +49(0)7143 271 94370, Email b.woelfling@hohenstein.de Serge Lang, Hohenstein Institut für Textilinnovation gGmbH, Schlosssteige I, 74357 Boennigheim, Baden-Württemberg, Germany,Tel +49(0)7I43 27I 8I I, Fax +49(0)7I43 27I 948II, Email Serge.Lang@hohenstein.de

Received: April 26, 202I | Published: May 10, 2021

Abbreviations: PR, pressure; LM, lateral motion; SC, static contact; LMC, Leap Motion Controller; SD, standard deviation; OEM, Original Equipment Manufacturer

\section{Introduction}

The development of high-quality products that simultaneously address the customer's needs is a key challenge for companies today. Before a customer buys a product, he or she often tests its characteristics by extensively recording the various sensory modalities (visual, acoustic, and haptic perception). ${ }^{1-3}$ Thus, the quality of a product is not only influenced by its technical and functional properties, but also by the subjective impression resulting from its sensory analysis. One aspect within this field is the haptic perception of quality, which determines the customer's appreciation and acceptance. ${ }^{4}$ Therefore, customer's haptic preferences and desires need to be identified. However, it is difficult to quantify and model human haptic perception using appropriate testing methods. This is due to the fact that the sense of touch is a strong subjective sensation, which combines different stimuli and is thus multimodal. ${ }^{5,6}$

In general, every modification also affects the nature of the material surface and can positively or negatively impair its haptic perception. Up to now, there has been no technical measurement that could objectively record and represent this sensory impression. Today, the assessment of product quality is largely carried out via test person studies with subjective results. A new prognosis method offers the potential to consider the haptic parameters relevant for the purchase decision already during the development of products and thus to improve the target accuracy and the speed of product development. In addition, the results of the technical measurement can also serve as an objective basis for quality and/or complaint discussions.

Due to the rapid development of autonomous driving, passengers have more and more time to occupy themselves with other things, including the feel of the materials used. The car interior is becoming more and more of a "feel-good oasis" and the haptics contribute a great deal to the sense of well-being. Therefore, measurement methods for quantifying the haptic properties of textile materials in automotive interiors were investigated and corresponding prediction models were developed.

\section{Material and methods}

\section{A. Touch and exploration procedures}

Humans are able to perceive many object properties by touch. Interactions between the hands and objects cause deformations, vibrations and temperature changes of the skin surface. This results in different information. The exact knowledge of the speeds and pressures that a person performs when exploring a surface are necessary for the later recording of the material characteristics. The literature classifies active and passive movement (McLinden \& McCall, 2016). Passive touch is when another person or object touches one. Active touch 
describes an intentional movement, usually performed with the hands, which implies an independent explorative and manipulative use of the skin. For the description of headliners and seat materials, which are always assessed in the installed condition, only the pressure (PR) for compliance; lateral motion (LM) for roughness; static contact (SC) for temperature are of relevance (Figure 1).

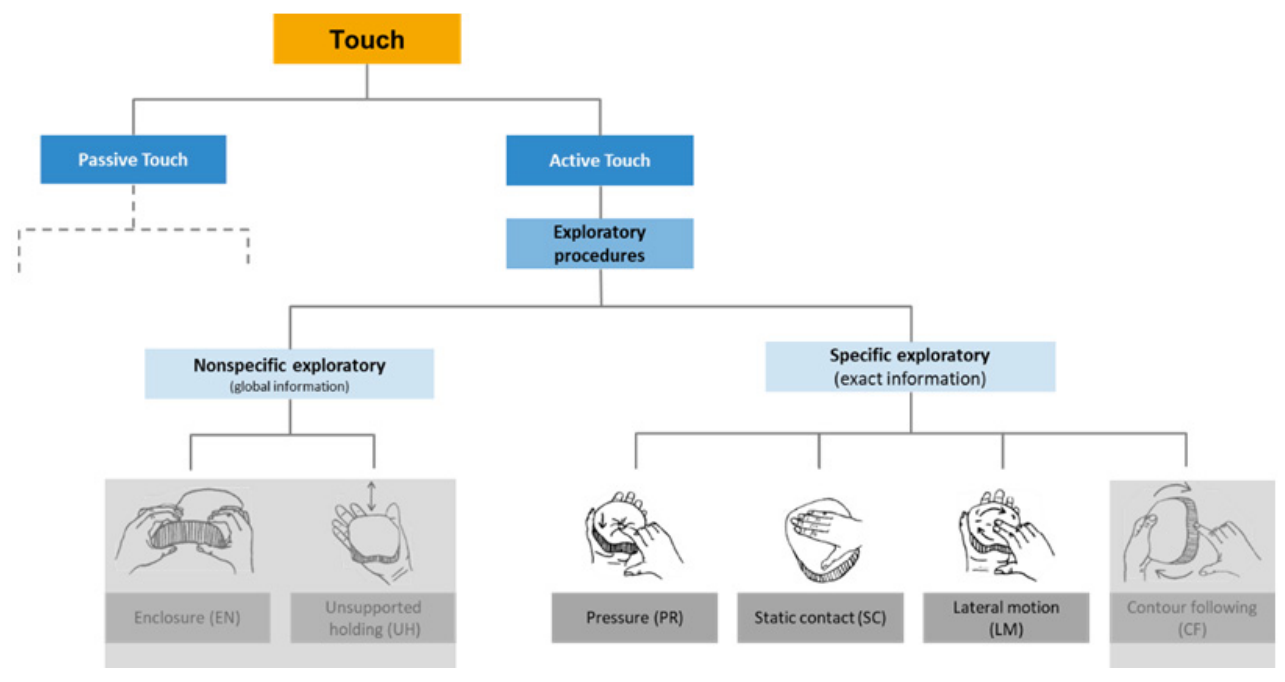

Figure I Exploration procedures. ${ }^{7-10}$

To record the exploratory movements and the human surface interaction, a Leap Motion Controller (LMC) and a textile pressure sensor (physiosense) from the company EMSU GmbH was applied. The textile sensor mat from EMSU is an embroidered yarn that is inserted into the fabric over an area of $15 \mathrm{~cm} \mathrm{x} 15 \mathrm{~cm}$ and is controlled via 1024 measuring points. The recording frequency of the sensor is $10 \mathrm{~Hz}$. The hardware of the LMC consists of two high-precision monochromatic infrared cameras and three separate infrared LED emitters. The LMC is able to track hand and finger movements (Figure 2), allowing to record information within a hundredth of a millimeter without any visible latency. The record rate is proximately 200 frames per second. ${ }^{11,12}$

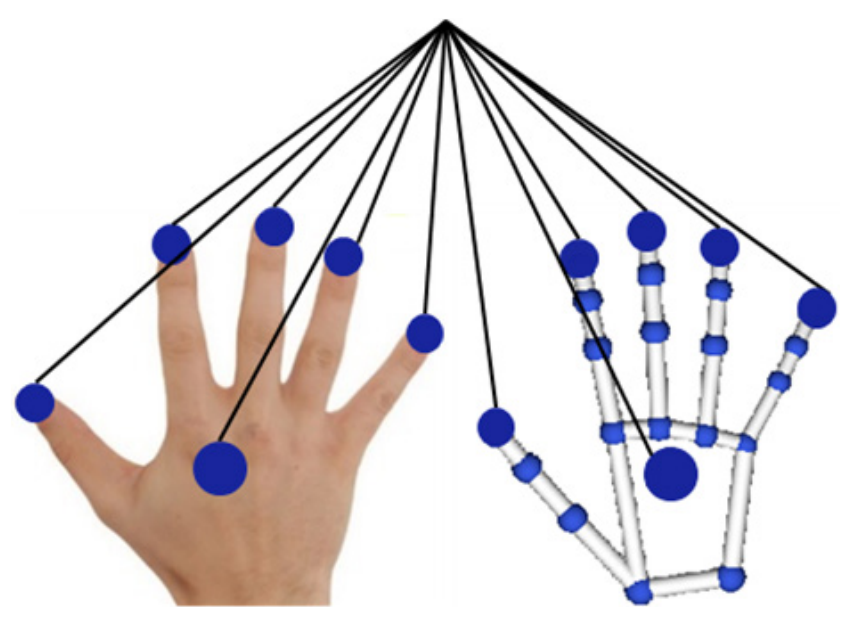

Figure 2 Measurement points on the hand LMC.

\section{B. Textile specific descriptors}

For communication between the material manufacturer, the supplier and the Original Equipment Manufacturer (OEM), clear descriptions (descriptors) are necessary to characterise the material properties. These material-specific descriptors enable the standardized recording and characterisation of the perceptual impression and also serve for unambiguous communication in subjective test person studies. The development of the textile-specific descriptors was based on an established procedure from sensory research.

\section{Materials}

Twenty-six materials from the automotive interior sector were used for the investigation, including 17 knitted fabrics, six woven fabrics, three nonwoven fabrics and one knitted fabric. The selection was based on various comparison criteria: Weaves, yarn or fiber fineness, number of filaments in the yarn composite. Laminated and non-laminated materials were also selected to determine the extent to which lamination influences the subjective impression in terms of softness and hardness. The selected materials for the main study are marked with an asterisk $\left(^{*}\right)$, those for the validation study with two asterisks $(* *)$ and are summarised in Table 1.

\section{Methods}

The methods listed in Table 2 were used to determine the objective, haptic properties of the materials. The skin sensory measurements (surface index $\mathrm{iO}$, wet cling index $\mathrm{iK}$, sorption index $\mathrm{iB}$, stiffness $\mathrm{s}$ and contact points $\mathrm{nK}$ ) and the measurements on the rheometer 
were performed at standard climate (DIN EN ISO 139:2011-10), $65 \%$ relative humidity and a temperature of $20^{\circ} \mathrm{C}$. The remaining measurements were carried out at specific standard climate for leather, $50 \%$ relative humidity and a temperature of $23^{\circ} \mathrm{C}$ (DIN EN ISO
2419). The human tactile parameters of pressure and speed, which were determined in A, were implemented as well as possible on the measuring devices.

Table I Material overview; materials used in * main study, ** materials used in validation study

\begin{tabular}{|c|c|c|c|c|c|}
\hline S. No & Ingredients & Construction & Purpose & Thickness & Grammage $\left[\mathrm{g} / \mathrm{m}^{2}\right]$ \\
\hline PT_M03* & $100 \%$ PES & Warp knitted, unlaminated & Headliner & 0,67 & III \\
\hline PT_M06* & $100 \%$ PES & Woven fabric, laminated & Child seat cover & 2,98 & 467 \\
\hline PT_MI6* & $100 \%$ PES & Weft knitted, laminated & $\begin{array}{l}\text { Accent stripes seat, seat back, } \\
\text { seat material }\end{array}$ & $|, 0|$ & 342 \\
\hline PT_MI7* & $100 \%$ PES & Weft knitted, unlaminated & Headliner & 0,73 & 174 \\
\hline PT_MI8* & $100 \%$ PES & Weft knitted, unlaminated & Headliner & 0,60 & 170 \\
\hline PT_MI9* & $100 \%$ PES & Weft knitted, unlaminated & Headliner & 0,54 & 170 \\
\hline PT_M20* & $100 \%$ PES & Weft knitted, laminated & $\begin{array}{l}\text { Accent stripes seat, seat back, } \\
\text { seat material }\end{array}$ & 1,29 & 443 \\
\hline PT_M2I* & $100 \%$ PES & Weft knitted, laminated & $\begin{array}{l}\text { Accent stripes seat, seat back, } \\
\text { seat material }\end{array}$ & 1,06 & 357 \\
\hline PT_M22* & $100 \%$ PES & Weft knitted, unlaminated & Headliner & 0,64 & 130 \\
\hline PT_M23* & $100 \%$ PES & Weft knitted, unlaminated & Seat material & 0,88 & 221 \\
\hline PT_M24* & $100 \%$ PES & Weft knitted, unlaminated & Seat material & $\mathrm{I}, 07$ & 270 \\
\hline PT_M25* & $100 \%$ PES & Weft knitted, unlaminated & Seat material & $|, 4|$ & 215 \\
\hline PT_M26* & $100 \%$ PES & Weft knitted, unlaminated & Headliner & 0,74 & 120 \\
\hline PT_M27* & $100 \%$ PES & Weft knitted, unlaminated & Seat material & 1,02 & 285 \\
\hline PT_M28* & $100 \%$ PES & Weft knitted, unlaminated & Headliner & 1,68 & 284 \\
\hline PT_M30* & $100 \%$ PES & Weft knitted, unlaminated & Headliner & 0,70 & 177 \\
\hline PT_M3I* & $100 \%$ PES & Weft knitted, unlaminated & Headliner & $\mathrm{I}, 33$ & 300 \\
\hline PT_M32* & $100 \%$ PES & Weft knitted, unlaminated & Door panel & 1,06 & 210 \\
\hline PT_M35* & $100 \%$ PES & Woven fabric, laminated & $\begin{array}{l}\text { Seat centre, accent stripes, } \\
\text { piping, door mirrors }\end{array}$ & 3,46 & 490 \\
\hline PT_M36* & $100 \%$ PES & Woven fabric, laminated & Seat centre & 3,62 & 701 \\
\hline PT_M46* & $100 \%$ PES & Woven fabric, laminated & $\begin{array}{l}\text { Seat, side panel, headrest, } \\
\text { centre armrest, door mirror }\end{array}$ & 3,00 & 360 \\
\hline PT_M47* & $100 \%$ PES & Woven fabric, laminated & Seat material & 3,00 & 458 \\
\hline PT_M48* & $\begin{array}{l}72 \% / 16 \% / 12 \% \\
\text { PA/WV/CV }\end{array}$ & Woven fabric, laminated & Seat material & 3,20 & 323 \\
\hline PT_M50* & $100 \%$ PES & Non-woven fabric, laminated & $\begin{array}{l}\text { Seat centre panel, accent } \\
\text { stripe, piping }\end{array}$ & 4,43 & 737 \\
\hline PT_M52* & $100 \%$ PES & Malivlies, non-finished & Headliner, series production & 2,37 & 230 \\
\hline PT_M53* & $\begin{array}{l}90 \% \text { PES/I0 \% } \\
\text { PES-bico }\end{array}$ & $\begin{array}{l}\text { Malivlies, non-woven fabric, } \\
\text { printed }\end{array}$ & Headliner, sample production & 2,23 & 200 \\
\hline PT_M54** & & Woven fabric & Seat material & 4,46 & 675 \\
\hline PT_M55** & & Woven fabric & Seat material & 3,99 & 590 \\
\hline PT_M56** & & Woven fabric & Seat material & 3,30 & 500 \\
\hline PT_M57** & & Woven fabric & Seat material & 3,74 & 532 \\
\hline PT_M58** & & Woven fabric & Seat material & 3,75 & 497 \\
\hline
\end{tabular}


Table 2 Methods/measuring devices/ characteristics/ measuring parameters/ descriptors

\begin{tabular}{|c|c|c|c|}
\hline Method/Measuring device & Characteristic & Measuring parameter & Descriptor \\
\hline I.Thickness/ & \multirow{2}{*}{ Thickness } & Weight I80g, & Hardness, \\
\hline \multirow[t]{2}{*}{ DIN EN ISO 5084} & & Measuring area $20 \mathrm{~cm}^{2}$ & Elasticity \\
\hline & \multirow{5}{*}{ Roughness parameters } & Normal force: $10,300 \mathrm{mN}$ & \\
\hline \multirow{4}{*}{ 2. Roughness/RoughTec } & & Velocity: $0.3,0.99 \mathrm{~mm} / \mathrm{s}$ & \multirow{4}{*}{$\begin{array}{l}\text { Roughness, directional } \\
\text { differences structure } \\
\text { height, structure regularity, } \\
\text { structure contour }\end{array}$} \\
\hline & & $40 \mathrm{~mm}$ travel & \\
\hline & & Ball stylus: I, $20 \mathrm{~mm}$ & \\
\hline & & Angles: $0^{\circ}, 30^{\circ}, 60^{\circ}, 90^{\circ}, 120^{\circ}, 150^{\circ}$ & \\
\hline 3. Static and sliding friction/ & & $2.4,6.6 \mathrm{~N}$ & \\
\hline \multirow[t]{4}{*}{ SSP-03 } & \multirow{3}{*}{ Static/ kinetic } & $1,80 \mathrm{~mm} / \mathrm{s}$ & \multirow{3}{*}{ Slipperiness } \\
\hline & & $20 \mathrm{~mm}$ & \\
\hline & & Haptic standard leather & \\
\hline & \multirow{4}{*}{ Penetration depth } & $3 \mathrm{~N}$ & Hardness, \\
\hline \multirow{3}{*}{ 4. Deformation/SoftTec } & & $0.3,2 \mathrm{~mm} / \mathrm{s}$ & \multirow[t]{3}{*}{ Elasticity } \\
\hline & & $20 \mathrm{~mm}$ ball stylus & \\
\hline & & With/without $4 \mathrm{~mm}$ foam & \\
\hline 5. Haptic touch temperature/HapTemp & Sensotact value & & Touch temperature \\
\hline \multirow[t]{2}{*}{ 6. Stiffness } & \multirow[t]{2}{*}{ stiffness } & \multirow[t]{2}{*}{ Sample: $2 \mathrm{~cm} \times 10 \mathrm{~cm}$} & Hardness, \\
\hline & & & Elasticity \\
\hline 7. Surface index & Surface index & Sample: $1 \mathrm{~cm} \times 10 \mathrm{~cm}$ & Quality impression \\
\hline \multirow[t]{2}{*}{ 8. Contact points/Textile topograph } & \multirow[t]{2}{*}{ Number of contact points } & Sample $6,25 \mathrm{~cm}^{2}$ & \multirow[t]{2}{*}{ Quality impression } \\
\hline & & Rotation angle $0^{\circ}, 90^{\circ}, 180^{\circ}, 270^{\circ}$ & \\
\hline 9. Wet cling index & Wet cling index & Speed: $3 \mathrm{~cm} / \mathrm{min}$ & Quality impression \\
\hline 10. Sorption index & Sorption index & measuring duration $600 \mathrm{~s}$ & Quality impression \\
\hline II. Rheometer/HAAKE MARS & Coefficient of friction & $\begin{array}{l}\text { Ring turning body: } 35 \mathrm{~mm} \text {, speed: } \\
1 \mathrm{~mm} / \mathrm{s} \text {, normal force } \mathrm{I}-20 \mathrm{~N}\end{array}$ & Slipperiness \\
\hline & & speed: I mm/s & \\
\hline
\end{tabular}

\section{E. Empirical studies}

In order to answer the research question: "Is it possible to forecast an assessment of the customer's perception of quality through measured values of technical parameters?" the influence of the technical parameters on the quality perception of the customers should be investigated in a sensory study. In total, three empirical studies were conducted on the textile surfaces. For the identification of the descriptors, a workshop (first study) was held with 10 people where the participants were first introduced to the topic of objective description. The participants were then presented with textile surfaces, which had to be described together using a uniform vocabulary. This process took place in 2 stages:

1st stage: Surface description based on previous results from the field of leather and artificial leather.

2nd stage: Validation of the procedure and verification of the uniqueness of the descriptors.

The second study was the main study to build a model between subjective and objective data, the third was the validation study.
The descriptors were introduced to all subjects prior the evaluation. Extreme examples were used to illustrate a descriptors maximum and minimum value in order to guarantee the realization of its actual span. Environmental effects, like wet hands or changing temperatures were controlled or suppressed by adequate means. The optical sense was switched off by having the test persons reach through a wall with holes to examine the samples. The surfaces were spanned on a hemisphere with foam patting underneath. The hemisphere was designed to induce a $5 \%$ surface expansion to the material, which is the usual elongation of textiles used in cars (Figure 3 ).

In addition the three dimensional presentation enables the subject to provide a more realistic judgment. The evaluation of the surfaces was done by means of digital questionnaires on the tablets placed in the study boxes. For this purpose, each descriptor had to be rated on a 7-point Likert scale by the test persons. Throughout the studies a total number of 26 textile surfaces (11 Headliner, 15 seat Material) were presented and evaluated. These 26 materials represent the crosssection of car interior textiles commonly used in practice. 116 subjects, 65 male and 51 female, participated in the study. The subjects were between 19 and 80 years old. 


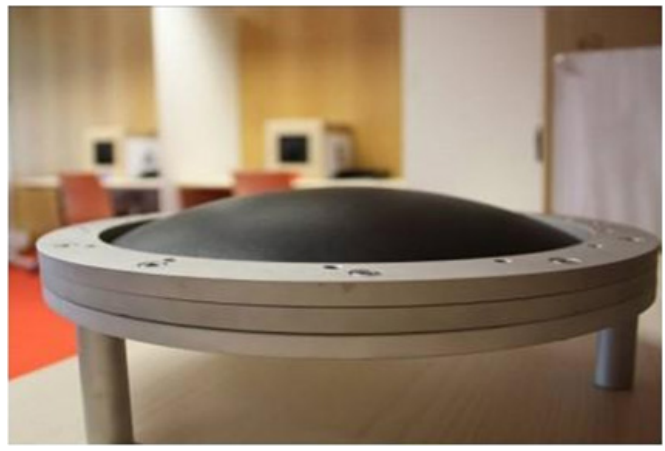

Figure 3 Hemisphere for material presentation.

The third study, the validation study, was conducted with 22 subjects, 15 male, 6 female, aged 21-59years. For this study, seating materials were selected that fit mainly within the range of the main study materials in terms of material properties. The study design was exactly the same as in the second study.

\section{Results}

\section{A. General results}

With the help of the Leap Motion Controller combined with the textile sensor mat, characteristic pressures and movement speeds of 15 test persons could be determined. On average, a mean pressure of $3.55 \mathrm{~N}+/-0,8 \mathrm{SD}$ and a mean speed of $0.13 \mathrm{~m} / \mathrm{s}+-0,04 \mathrm{SD}$ were obtained for the lateral movement.

For better communication along the supply chain, textile descriptors were developed in the first study. The different descriptors, together with their assigned minima and maxima are shown in Figure 4.

\begin{tabular}{|c|}
\hline Descriptor \\
\hline Initial tem perature sensation \\
\hline Roughness \\
Directional difference \\
Structural regularity \\
Structure height \\
Structure contour \\
\hline Slipperiness \\
Elasticity \\
Hardness \\
Quality impression
\end{tabular}

Figure 4 Textile descriptors with their minima and maxima.

The materials were characterized using the methods shown in Table 2. In the following, the results of the methods are shown, which are necessary according to the correlation analysis for the description of the haptic sensation of textile materials in automotive interiors.

The thicknesses $\mathrm{D}$ of the used materials without lamination range from $0.5 \mathrm{~mm}-1.68 \mathrm{~mm}$. For the materials with lamination, the thicknesses are highly dependent on the lamination material, such as foams, nonwovens and range from $0.55 \mathrm{~mm}-4.43 \mathrm{~mm}$.

The bending stiffness was determined according to the Hohenstein test specification. In each case, the right and left side as well as the wrap/weft direction were considered. For the unlaminated materials, values between $11.9^{\circ}$ and $64.2^{\circ}$ were measured, laminated materials again showed higher values overall and laid between $49.0^{\circ}$ and $90^{\circ}$ The higher the value, the stiffer the material. The bending angle $90^{\circ}$ represents the maximum value of this measurement.

Using the rheometer HAAKE MARS, the friction force Ff and the friction coefficient (static/kinetic) of the materials could be determined. To investigate the friction behavior of the materials, ring rotors were rotated on the materials at loading pressures of $1 \mathrm{~N}$, $5 \mathrm{~N}, 10 \mathrm{~N}, 15 \mathrm{~N}$ and $20 \mathrm{~N}$ for 60 seconds at a speed of $1 \mathrm{~mm} / \mathrm{s}$. Friction is lower on materials with longer protruding fibers, such as the nonwovens, than on "smoother" materials. This could be due to the protruding fiber ends, which move somewhat with the rotation of the measuring geometry and thus provide lower friction. At higher loading pressures, the coefficients of friction are lower than at lower loading pressures. For example, at load pressures of $1 \mathrm{~N}$, the coefficients of friction average 0.426 for fabrics and only 0.193 for a load pressure of $20 \mathrm{~N}$.

With the SoftTec, it is possible to recreate the hardness that a person feels when touching surfaces. A ball stylus (20 mm diameter) is applied vertically to the specimen. The material thickness, the penetration depth and a force-displacement diagram are output. The measurement parameters of $3 \mathrm{~N}$ normal force and $2 \mathrm{~mm} / \mathrm{s}$ velocity were chosen based on the results of the exploration movement tests. Penetration depths between $20 \%$ and $75 \%$ were measured for the different textiles.

The measuring principle of the RoughTec is based on the stylus method. The surface of the specimen is traversed with different probes, loads and speeds. The measurement was carried out in accordance with DIN EN ISO 4287. The slowest speed, the lowest load and the smallest stylus can be used to record the actual roughness of the material most accurately. For the roughness parameter Rt, values were measured in a range from 100 to $600 \mu \mathrm{m}$. However, this roughness does not necessarily have to correspond to the perceived roughness. For this reason, further roughness measurements were carried out with a stylus like the fingertips (20mm ball stylus), the maximum measuring speed of the instrument of $1 \mathrm{~mm} / \mathrm{s}$ and a load of $3000 \mathrm{mN}$. These measurement parameters were chosen based on the results of the exploration motion studies. During these measurements, some materials experienced snagging of the sample with the textile. Thus, these measurement settings are not to be considered as purposeful. All other measurement results were considered in the correlation analyses. 


\section{B. Correlation analysis}

In order to validate the human studies according to the relationship between the subjective and the objective parameters a Pearson's correlation coefficient was used to analyze the correlative relationships. In the case of psychological questionnaire data, values of 0.3 and above are referred to as a low correlation, values of 0.5 and above are referred to as a good correlation, and values above 0.7 are referred to as a (very) high correlation. The analysis was performed for the correlation between the descriptors of the subjective study and the objective material parameters. It was done separately for the seat materials as well as for the headliner materials. The measured objective roughness parameters ( $\mathrm{Ra}, \mathrm{Rt}, \mathrm{Rz}$ ) correlate between good and very high for the seat materials with the subjective statements on the descriptors belonging to roughness $(0.64$ to $0.86, n=15, p<0.05)$. In the case of headliner materials, the texture height descriptor correlates good $(0.70$ to $0.85, \mathrm{n}=11, \mathrm{p}<0.05)$. For all 4 descriptors (roughness, directional differences, texture height, scratchiness), a positive correlation is observed. Exactly the opposite is true for the perceived elasticity. The lower the perceived elasticity, the higher the measured stiffness $(-0.71$ to $-0.95, \mathrm{n}=15, \mathrm{p}<0.05)$. Another negative correlation was found for perceived temperature and measured stiffness $(-0.68$, $\mathrm{n}=15, \mathrm{p}<0.05)$. This means that stiffer materials feel colder. This could be explained by creating a higher contact surface while touching the surface. In total the correlation between subjective and the objective parameters lead to good relationship between the variables. This is necessary to perform the second step to find a prognosis model, based on objective parameters.

\section{Multiple regression analysis}

While correlation calculation determines the strength of a linear relationship between two items, regression analysis determines the functional relationship between several quantitative items. The scope of the work is to objectivate the subjective ratings with an easy to use prognosis model. Here, the characteristic Y (perceived quality) is considered as a dependent variable of the independent influencing variables $X$ (physical characteristics). The aim of the analysis is to achieve the best possible agreement for the perceived quality with as few physical parameters as possible. A sequencial multiple regression analysis was used to match the best number of variables, always compared with the coefficient of determination. Of the 19 different physiological parameters available, the five with the highest predictive power were selected using regression. In the end these five variables represent a reasonable amount of measurement to use to predict perceived quality very well. Seat materials (SM) were analyzed separately from headliner materials (HM). After the multiple linear regression, the following model is obtained for predicting the quality perception of the respective material.

$$
\begin{aligned}
& \text { Quality }_{\mathrm{HL}}=-0.907+1.778 * \mathrm{~d}+0.002 * \mathrm{~S}_{\mathrm{F}}+0.001 * \mathrm{i}_{\mathrm{B}}-0.093 * \mathrm{~S}_{\mathrm{K}} \\
& +22.987 * \mu_{20}(1) \\
& \text { Quality }_{\mathrm{SM}}=6.090+0.240 * \mathrm{~d}-0.009 * \mathrm{R}_{\mathrm{t}}+0.007 * \mathrm{R}_{\mathrm{z}}+0.668 * \mu_{1}- \\
& 8.552 * \mu_{20}(2)
\end{aligned}
$$

With d thickness $[\mathrm{mm}], \mathrm{S}_{\mathrm{F}}$ deformation characteristic $[\mathrm{mN}], \mathrm{i}_{\mathrm{B}}$ wetting index $[\mathrm{s}], \mathrm{S}_{\mathrm{K}}$ warp direction stiffness $\left[{ }^{\circ}\right]$,

$\mu_{1} ; \mu_{20}$ coefficient of friction at $1 \mathrm{~N} \& 20 \mathrm{~N}, \mathrm{R}_{\mathrm{t}}$ roughness depth $[\mu \mathrm{m}], \mathrm{R}_{\mathrm{z}}$ average roughness depth $[\mu \mathrm{m}]$

It should be noted that the best individual correlations combined do not necessarily result in the best prediction of quality. For the headliner materials (Figure 5), the model has a prediction quality of almost $98 \%(n=11, p<0.05)$. The prediction quality of the perceived quality of the seat materials is just under $80 \%(\mathrm{n}=15, \mathrm{p}<0.05)$. Therefore, it is possible to predict the perceived quality on the base of objective parameters.

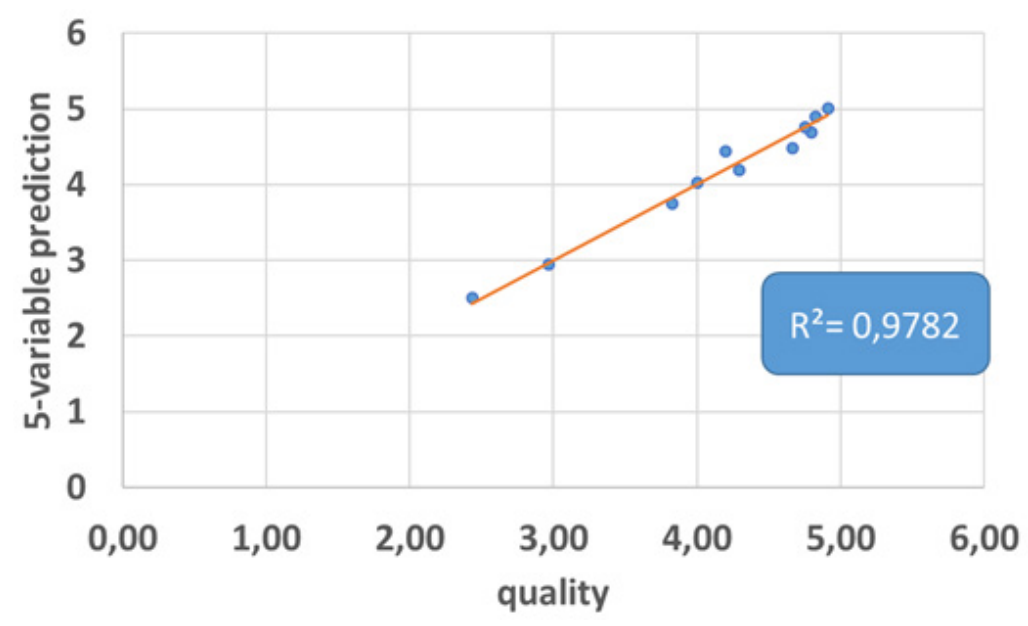

Figure 5 Comparison of predicted quality perception ( $y$-axis) vs. test person statement (x-axis) - headliner materials.

To validate the created model, a third study was conducted. The five physical characteristics from the model were recorded. The determined material characteristics were now used in the formula for the seat materials and plotted against the assessment of the test person study. For four of the five materials, predicted quality and the test persons' statements fit.

\section{Discussion}

A thorough understanding of human exploration of surfaces and haptic perception will help improve the sensory design process of products. ${ }^{13}$ Domains that are strongly associated with haptics (e.g. touch screens) could benefit from this knowledge. To this end, the LMC was used to investigate specific hand movement sequences and hand velocities during the exploration of a textile surface. To fully capture exploration movements, we determined the measurement of the pressure a human exerts to explore a surface. To do this, we combined the LMC with a textile sensor mat and fused the data.

Overall, the results obtained in this research project represent an advance for the objectification of subjective surface descriptions. Each subjective description of a surface could be assigned to one or more 
objectively measured technical parameters. For several descriptors, a correlation was found between the objectively measured technical parameters and the subjects' evaluation. Furthermore, this work shows a concept for the prediction of haptically perceived textile quality with the help of objective measurements.

Previous metrological approaches to objectively assess the haptic sensation of a textile mostly work with the approaches of touching the fingertips or gripping a textile with the whole hand. ${ }^{14,15}$ However, in the case of cover materials, it is no longer possible to grab the material with the whole hand, because they are built in. In addition, these approaches usually only consider the material properties (technical parameters) in isolation and do not establish a connection to the perception of quality. The same concept is used in. ${ }^{16}$ Five texture, two friction, five deformation, two thermal and one adhesion parameters are determined and assigned to a reference scale. This makes it possible to classify the materials among themselves, but there is no prediction possibility of human perception. In our model, the objective parameters are used to predict the human perception of quality. In addition, we were able to set up various statistical models to predict the haptic textile surface quality. We created an all-encompassing model for car interior textiles and were also able to create separate models for headliners and seat materials with even higher predictive power.

\section{Conclusion}

Based on the proposed results it can be confirmed that data based statistical models can predict which textile materials would be preferred by the customer. This paper also shows that subjective perceived haptic surfaces quality can be measured objectively by using different measurement systems. This approach can be used in the product development process to predict and validate the haptic surface perception of, for example, newly developed products. This type of surface validation of textiles helps manufacturers to predict how the customer will accept the material before it reaches the market. Consequently, this information could create value for the manufacturer.

However, one has to keep in mind that the best haptic surface does not directly mean that the customer wants to buy the surface. The human perception is multisensory by nature therefore in the future a multisensory databased model which includes the acoustic and optical senses should be considered in order to predict human surface perception.

\section{Acknowledgments}

IGF project $19326 \mathrm{BG}$ was founded through the AiF within the framework of the program for promotion of cooperative industrial research (IGF) by the German Federal Ministry for Economic Affairs and Energy based on a resolution by the German Bundestag.

\section{Funding}

German Federal Ministry for Economic Affairs and Energy based on a resolution by the German Bundestag.

\section{Conflicts of interest}

Author's declares that there is no conflict of interest.

\section{References}

1. Fujisaki W, Tokita M, Kariya K. Perception of the material properties of wood based on vision, audition, and touch. Vision research. 2015;109:185200 .

2. Baumgartner E, Wiebel CB, Gegenfurtner KR. Visual and haptic representations of material properties. Multisensory Research. 2013;26(5):429-455.

3. Wijntjes MWA, Xiao B, Volcic R. Visual communication of how fabrics feel. JoV. 2019;19(2):1-11.

4. Bi W, Jin P, Nienborg H, et al. Estimating mechanical properties of cloth from videos using dense motion trajectories: Human psychophysics and machine learning. J Vis. 2018;18(5):12.

5. Ruzas S. Lebenssinn: Wie wir uns die Welt ertasten. 2015.

6. Fishel JA, Loeb GE. Sensing tactile microvibrations with the BioTac - comparison with human sensitivity. The Fourth IEEE RAS/EMBS International Conference on Biomedical Robotics and Biomechatronics. Rom, Italien, 2012.

7. Jansen SEM, Bergmann Tiest WM, Kappers AML. Identifying haptic exploratory procedures by analyzing hand dynamics and contact force. IEEE transactions on haptics. 2013;6(4):464-472.

8. Lederman SJ, Klatzky RL. Extracting object properties through haptic exploration. Acta Psychologica. 1993;84(1):29-40.

9. Theurel A, Frileux S, Hatwell Y, et al. The haptic recognition of geometrical shapes in congenitally blind and blindfolded adolescents: Is there a haptic prototype effect? PloS one. 2012;7(6):e40251.

10. Withagen A, Vervloed MPJ, Janssen NM, et al. The Tactual Profile: Development of a procedure to assess the tactual functioning of children who are blind. British Journal of Visual Impairment. 2009;27(3) :221238.

11. Mohandes M, Aliyu S, Deriche M. Prototype Arabic sign language recognition using multi-sensor data fusion of two leap motion controllers. NJ: Piscataway; 2015

12. Chan A, Halevi T, Memon N. Leap Motion Controller for Authentication via Hand Geometry and Gestures. In: Tryfonas T, Askoxylakis I, editors. Lecture notes in computer science. human aspects of information security, privacy, and trust. Cham: Springer International Publishing; 2015;9190:13-22.

13. Jansen SEM, Bergmann Tiest WM, Kappers AML. Identifying haptic exploratory procedures by analyzing hand dynamics and contact force. IEEE transactions on haptics. 2013;6(4):464-472.

14. De Boos A, Tester D. SiroFast, fabric assurance by simple testing, Report No. WT92.02, 1984.

15. Kawabata S. The standardization and analysis of hand evaluation. 2nd Edn. The Textile Machinery Society of Japan; 1980.

16. Loeb GE. Quantifying human touch and feel without humans. Stuttgart: Automotive Interiors Expo; 2016. 